\title{
A Comparative Study of Curriculum and Classroom Form between Chinese and Japanese Universities--Take Chiba University, Waseda University as an Example
}

\author{
Li Jiaze ${ }^{1}$, Li Yang *, ${ }^{\text {, You Yiming }}{ }^{1}$ \\ ${ }^{1}$ School of foreign languages, Nanjing Agricultural University, Nanjing, Jiangsu, 210026 \\ ${ }^{2}$ School of management, Nanjing Forest Police College, Nanjing, Jiangsu, 210023
}

Keywords: Sino Japanese University; curriculum; classroom form; personnel training; innovation

\begin{abstract}
With the rapid development of science and technology, the importance of education has become increasingly prominent. Japan's education investment ranks first in the world. The emphasis on education has made Japan a world leader in many fields, such as mechanical engineering, automobile manufacturing, electronics, IT, chemistry, biology, economics, animation, media, architecture, design, etc. The complete legal guarantee system and policy guidance also made the Japanese education system develop healthfully. After three educational reforms, Japanese higher education has the characteristics of diversity and openness, and Japan has gradually become the best choice for overseas students to study abroad.
\end{abstract}

This article will discuss the form of university classroom after the reform of higher education in Japan. From the perspective of Chinese and Japanese students and exchange students, this paper explores and compares the differences and similarities between Chinese and Japanese University education, talent training direction and classroom forms. This paper explores the motive power of talent cultivation and Its Enlightenment to China's higher education behind the rapid development of Japan's advanced science and technology.

During his study in Japan, the first author and his team participated in the elective courses of Chiba University and Waseda University respectively. Especially taking the two Japanese universities as examples, taking "teaching and learning" as the main line, this paper makes a comparative analysis of the similarities and differences between Chinese and Japanese university classroom forms from the aspects of curriculum preparation, teaching methods, curriculum feedback and so on.

\section{Curriculum preparation: curriculum planning}

Detailed introduction to curriculum planning. In the public optional courses of Chiba University and Waseda University and the language courses open to international students, the first course of each subject provides information about the course to the students. This paper introduces in detail the study contents of the subjects, the course planning, the objectives to be achieved at the end of the semester, the bibliography of the courses, the evaluation methods of the examinations, and the personal information and contact methods of the teachers. This information is very useful throughout the semester. According to their own preferences to choose their own courses, more freedom to choose courses, learning content is also easy to have a stronger interest. If you can't attend the first course, you can get the complete course information and the teacher's teaching information after you log in the student account on the school's official course retrieval website, the syllabus[1].

An investigation of personal learning intention. In the first course, Japanese teachers will send course plans to elective students. Since the content of the curriculum plan is set according to the course learning situation of the students selected in the past, teachers will also issue a questionnaire on individual learning intentions to the current students. In the course of Japanese Literature at Chiba University in which the author participated, the teachers also distributed questionnaires on students'learning intentions. In the question of "works that I hope to study in class", the author fills in the suspense novels which I like very much in Japan randomly, and hopes that the works of the 
author, Kiyo Tono, can be read together in class. Unexpectedly, in the course plan book issued for the second course, it was written that the two courses would be used to study an excerpt from a work by Kiyo Tono[2].

Students' self selection. In addition to course information, Japanese teachers will also have questionnaires on classroom form. Understand the students' generally accepted teaching methods and the classroom form expected. According to the questionnaires, teachers will adjust the learning content and form of the classroom, and make a teaching plan that conforms to the students'interests. It is not only in the content of the course, but also in the choice of classroom form.

In contrast, the preparatory work of Chinese universities is slightly inadequate. The overall progress of the course is in the hands of the teacher, and the students follow the content and rhythm of the teacher's teaching. Little is known about the overall planning and arrangement of the curriculum. In addition, from the questionnaires on the subjects received, it is found that many Chinese College students, especially when choosing elective courses, often choose subjects only on the basis of the name of the course or the teacher's score, but the content of the course is in the clouds. In the subsequent courses, it was found that the content of the selected courses did not conform to the individual learning intention, and could not obtain the real knowledge promotion. Information acquisition is inefficient, and it is difficult to form a whole knowledge framework, thus affecting students'autonomous learning.

\section{Curriculum content and classroom form}

The selection of teaching materials and contents of courses in Nihon University are constantly changing. For a subject, there are few unique and fixed textbooks. Most of them will only list the relevant bibliography of the course, and the teachers will select and plan the learning content of the course and distribute it to the students in the form of lecture notes. The content of each semester will also be adjusted according to the questionnaire of students' personal learning intention. Students have the right to choose their own content independently.

The diversification of classroom form is also a highlight of Nihon University classroom. In addition to theoretical study of professional knowledge, practical courses occupy a large proportion. This mode of classroom teaching, consciously arranging students to participate in the entire teaching activities, to cultivate students'divergent thinking, to live a more comprehensive professional knowledge. Rich classroom forms and frequent teacher-student interaction enable students to truly participate in the classroom interest in learning, better absorption of professional knowledge.

In the classroom of Nihon University, the work of teachers is to guide students in professional orientation. Equal communication between teachers and students has created a relaxed learning atmosphere. Apart from the correctness, teachers are absolutely respectful to students' personal thinking. For the vast majority of questions, teachers are more likely to get the individual thoughts of the students after independent analysis than the correct answers. Compared with unilateral teaching, it is more like a study between teachers and students. At the end of the exchange, analyze the crux of the problem one by one, and timely feedback to students, so that knowledge is consolidated and strengthened[3].

In the classroom teaching of contemporary Chinese universities, teachers and students tend to be traditional "master slave" relationship. Teachers are still in the presence of knowledge authority, passing the ready-made knowledge to students through lectures. Teachers mainly rely on the "teacher talk - students listen" way to complete teaching activities, the teaching goal of teachers is to achieve knowledge transfer. Students take notes in class, take notes in exams, lack of initiative in learning, is not conducive to the cultivation of students'independent spirit and practical ability. In addition, the teaching method is also faced with an unavoidable practical dilemma: students'long-term attendance leads to decreased attention, affecting the effect of listening. This kind of teaching method is easy to cause students to resist psychology, at the same time, it also lacks the training of students'ability to think independently. 


\section{Curriculum feedback and teacher's teaching improvement}

After the end of each session, Japanese teachers will receive students' feedback in different ways. The purpose is to understand students' mastery of curriculum contents and personal opinions on curriculum. Some finish a summary report at the end of the course, or write a paragraph about the experience of the next course. Others are presented in the form of homework. This kind of written communication can not only let teachers know the students'knowledge in real time, and adjust their teaching progress and direction appropriately, but also more importantly, teachers' positive and immediate response to students'questions can shorten the distance between teachers and students, and deepen the communication between teachers and students.

In Japanese universities, the last course before the mid-term final exam for each subject is given a "Curriculum Evaluation Questionnaire". In recent years, college students as teaching subjects to participate in teacher teaching evaluation has also become a widely used way of teaching evaluation in China's colleges and universities. Whether students can participate in the evaluation of teaching is not the key to the problem, the key is how to effectively organize the evaluation of teaching, so that the evaluation activities can truly improve teaching and improve the teaching effect. The evaluation of teaching in Chinese universities is mainly about the evaluation of teaching work and quality of teachers. Whether teachers respond to the questions raised by students in the mid-term curriculum evaluation questionnaire and make corresponding adjustments in the second half of the semester is also a key part of the evaluation. For teachers, this questionnaire can help to revise their new semester curriculum planning and improve the teaching content.

\section{The composition of scores and the direction of personnel training.}

Japanese university teachers determine the performance of students in many ways. Examination scores account for only a small proportion of the final course examination, Japanese university teachers tend to allow students to report their learning results, in the form of publications and papers instead of a unified examination. There is no standardized and unified correct answer, the process of finding the answer and careful research ideas are what Japanese teachers want to see. In contrast, many colleges and universities in China still adopt the traditional evaluation method-summative evaluation. The evaluation is usually carried out at the end of the course or the end of the semester. The final examination score is used as the criterion to judge students'academic performance. Students' learning is mainly to cope with the examination, and has no direct relationship with the learning process. This evaluation method has obvious limitations, which weakens the enthusiasm and initiative of students, and is not conducive to the healthy growth and overall development of students. In recent years, many colleges and universities have diversified teaching innovation in student achievement evaluation. Although the score is no longer regarded as the sole criterion, it still occupies a large proportion.

Japanese universities attach great importance to the cultivation of students'practical ability and practical ability, and have a very clear talent distribution system and talent training objectives. The undergraduate teaching stage in Japan is mainly based on "comprehensive upbringing" and "initial guidance for Majors". It not only enables students to realize their preliminary knowledge of their majors, but also makes efforts to cultivate their comprehensive abilities. After entering the third year, the professional orientation will be carefully divided and classified. Part of the students who are determined to continue to do research, and have certain prospects for professional development will be guided to master's doctoral stage for in-depth theoretical study and professional research; students who want to enter the workplace directly after graduation for practical professional knowledge guidance. The student union will be assigned to a designated laboratory to conduct personal research under the guidance of a tutor. Compared with traditional courses, Japanese higher education attaches more importance to practical courses and acquires competence in laboratories and social practice. In addition, Japanese teachers focus on developing students' research and independent thinking ability. In homework, more attention is paid to students'independent analysis and research, as well as the logical narrative report of the research results. Many of them allow 
students to choose their own topics and decide on the various elements of the project, and finally present the entire research process and final conclusions to the tutor. Of course, the results are not the most important. Japanese teachers pay more attention to the process of students'knowledge exploration than to the acquisition of knowledge.

\section{Inspire and sublimate}

The perfect curriculum preparation in Japanese universities has given us great inspiration. Perfect logistics education and teaching work: first, curriculum planning is specific and open: formulate a complete curriculum planning, including teaching plan, teaching content, performance evaluation, learning materials, and so on, and publish to students; second, immediate curriculum feedback work. Teachers'teaching task is not only to grant knowledge, but also to know students' mastery of the course content and make corresponding teaching adjustments. Third, the evaluation system of scientific learning achievements. We should improve the evaluation criteria for students' achievements, conduct a diversified evaluation of students' abilities, and change the current situation of students' examination oriented learning. Fourth, improve the network assisted teaching system. Through online feedback after class, teachers can help students understand their learning and adjust their teaching plans. By issuing online teaching notices, the teaching tasks can be arranged in real time to improve teaching contents. Promote communication between teachers and students online after class.

Change the traditional habit of simple teaching. Advocate equal dialogue between teachers and students, so that teachers are no longer just knowledge authorities and managers, but to become dialogue guides, listeners and collaborators. Teachers' responsibilities should increasingly turn to stimulating thinking; they should concentrate more time and energy on creative activities that influence, discuss, motivate, understand and inspire each other. Teachers should no longer be the kind of supervisors and controllers outside the students in traditional teaching, but should provide guidance, explanation, advice, criticism and encouragement when students study. The creative thinking of students should be stimulated and encouraged in the whole process of teaching. Teachers should strengthen communication and communication with students and provide more opportunities for interactive learning. We should promote the application of information technology in teaching and enhance students' ability to use network resources. Give full play to the advantages of multimedia graphics and text, set text, graphics, animation, video, music in one, to bring more information and more intuitive image to the classroom, solve those phenomena and theories that can not be expressed in traditional teaching, difficult to explain, so that students can better perceive and understand abstract knowledge. In addition, we should strengthen practice training and improve students' practical ability. The course practice, teaching practice and off-campus study are integrated into the various stages and links of university personnel training to provide students with different learning environment and practice experience. In addition to self-built practice base, colleges and universities should actively expand friendly cooperative relations with all sectors of society, develop off-campus practice base, realize the normalization of cooperation, and provide strong external support for the cultivation of talents'practical ability.

In the undergraduate education stage, we should not only cultivate students'professional basic ability, but also attach importance to cultivating students' independent subject exploration ability and logical analysis and generalization ability. "Problem Exploration Ability" mainly refers to the ability to respond to changes actively, to explore and study professional topics independently, and to make flexible and comprehensive judgments on topics from a broad perspective. Attaching importance to education and comprehensive personnel training, broadening students'academic horizons, cultivating students' thinking ability, so that students have the ability to see problems from different angles, independent and comprehensive thinking after accurate judgment. Cultivate students'rich personality, so that students can position their knowledge and life from the relationship with society. Professional education should also carry out the basic spirit of education and attach importance to the "foundation and basic" by teaching students the relationship between the various related disciplines, academic and personal life and social relations, to cultivate students'initiative to 
explore and solve the basic ability of the subject[4].

In the final analysis, the competition between nations is the competition between education and talents. China has entered a critical period of deepening reform, transforming and developing, enhancing innovation ability, and realizing the transformation and upgrading of industrial structure. The realization of these changes largely depends on the cultivation of high-quality talents. "If we manage the world differently, we will not rule the country." For modern China, the reform of higher education is a long way to go. There are still some gaps between China and Japan, Europe and the United States in many aspects, and there are still many loopholes and deficiencies in the talent training model. Making the past serve the present and making foreign things serve China. We should actively learn from the successful experience of Japan's post-war education reform, learn from each other's strengths, respect knowledge and talents, regard education as the foundation of national rejuvenation, absorb western science and technology, carry forward the cultural essence of the Chinese nation and promote the cultivation of high-quality talents in China. It can be predicted that in the near future, China's outstanding scientific and technological innovators will also be able to stand in the forest of the world, blooming brilliant light.

\section{References:}

[1] Li Jiaze, Yu Ming Ming. A comparative study of teaching modes in Chinese and Japanese universities, [J]., culture and education materials, 2017, (21): 194-195

[2] Wen Yaguang. Successive Educational Reforms in Japan and Their Enlightenment to China's Basic Education Reform. Northwest Adult Education Journal, 2007, 3:68-69.

[3] Shen Hongmei. The Enlightenment of Japan's three educational reform on China's education reform [J]. Examination week, 2012 (90): 19-21.

[4] Li Jie. Characteristics and Enlightenment of classroom teaching mode in Nihon University [J]. Journal of Changchun University, 2007 (04): 89-91.

[5] Project: National Undergraduate Innovation and entrepreneurship training program support project (201710307076)

About the author:

1. Li Jiaze (1997.8-), female, Zhuang, Nanjing, Jiangsu Province, 2015 undergraduate students, research direction: Sino-Japanese language and culture comparison, Japanese primary and secondary school food and education

2. Li Yang (1972.11-), male, Zhuang, Nanjing, Jiangsu Province, doctor (later), associate professor, research direction: traditional culture and applied psychology, organizational behavior and physical and mental health management

3. You Yi Ming (1965.2-), male, Han nationality, Nanjing, Jiangsu Province, associate professor, doctor,research direction: Sino-Japanese language and culture comparison, Japanese agricultural development history.

Communication Author: Li Yang, Address: 28 Wenlan Road, Qixia District, Nanjing, Jiangsu Province 